\title{
Research on the Practice of Innovation and Entrepreneurship of Students Majoring in Automation and Control in Higher Vocational Colleges
}

\author{
Shengsheng Wang \\ School of Electrical and Information Technology Jilin Vocational and Technical College of Industry, \\ Jilin, China
}

\begin{abstract}
Investigate the main links of higher vocational automation and control majors, such as training objectives, curriculum settings, and practical arrangements, in-depth analysis of the status quo of professional students' engineering practice ability, and point out the key issues. The article puts forward the idea of establishing a practical ability training platform with innovation and entrepreneurship as the main driving force. At the same time, the author combines the society's demand for "innovative and entrepreneurial talents" and the entrepreneurial characteristics of higher vocational automation and control, based on the Java web cloud application design scheme, design a set of higher vocational students' innovation and entrepreneurship system, which can better support higher vocational students' innovation "Entrepreneurship" scientific research and training project management, more scientifically guide the smooth development of "innovation and entrepreneurship education" in higher vocational schools.
\end{abstract}

Keywords: Higher Vocational; Automation Control; Innovation and Entrepreneurship; System Design.

\section{Introduction}

At present, the automation control industry is a sunrise industry in the new century, and is listed as one of the priority pillar industries in the world. Chinese automation control industry has entered a period of rapid development, and it has had an important impact on the development of higher education in China. In recent years, Chinese higher vocational education has also been developing rapidly. The combination of work and study has received more and more attention in the fields of higher education and vocational education. Combination of Teaching, Combination of Work and Study", by October 28, 2005, the "Decision of the State Council on Vigorously Developing Vocational Education", once again emphasized the need to change the school and classroom-centered talent training model, and vigorously promote the combination of work and study, part-time work and part-time study. system. The function of the combination of work and study mode is mainly to improve the professional quality of students. Choosing the combination of work and study can reflect the combination of work and study to improve students' professional quality, improve students' professional skills, curriculum reform, and team construction with a dual-teacher structure [1]. After the graduates of higher vocational colleges are employed, most of the students go to the front line of production and need to develop the teaching of higher vocational automation control courses. At present, many higher vocational and undergraduate colleges and universities have carried out many constructions on the automation control technology training platform, forming a variety of experimental training teaching research platforms. According to the requirements of professional construction and reform based on the systematic work process of the vocational technical college, the automation control major has gradually formed a new type of talent training program composed of basic professional skills and professional development and migration capabilities. According to the automation and control talent training plan, it is urgent to develop a production-oriented worklearning automation control training platform to meet the requirements for training automation and control talents. 


\section{Current Status and Problems of Professional Talent Training}

\subsection{The Setting of Innovative Curriculum Practice Links Needs to be Optimized}

The automation control profession is very practical, and it is necessary to carry out the teaching of engineering design and construction skills in the teaching process. Although some courses of this major set up in-class experiments, they are often limited to confirmatory experiments, and the ratio of comprehensive and design experiments is not high [2]. Moreover, because the practice of professional courses failed to be set in accordance with the social needs of the new era, there has been a certain disconnect between the setting of practical links and social needs.

\subsection{Diversified Professional Training Methods Urgently Need to be Deepened}

At this stage, the talent training model of higher vocational schools still adopts a single talent training method that tends to be integrated. The teaching and learning methods are single, and the "one-way indoctrination" and "crawling" teaching modes ignore the students' subjective initiative and personality cultivation, ignore the market's demand for talents, and run counter to the needs of students' personalized training, which limits it to a certain extent. Students' knowledge acquisition and ability improvement. Therefore, it is necessary to explore engineering + diversified training methods to provide students with "individualized" and "customized" education.

\subsection{The Construction of Professional Innovation and Entrepreneurship Platform Needs to be Improved}

The entrepreneurial practice process is a comprehensive practice process that incorporates innovative elements, uses entrepreneurial methods, and develops entrepreneurial skills. Strengthening the construction of innovation and entrepreneurship platforms is a practical need for innovation and entrepreneurship. Therefore, higher vocational schools are inevitably required to build a platform for innovation and entrepreneurship to realize the connection between the teaching process and the production process [3]. And because students of different majors and different grades have different needs for innovation and entrepreneurship, the functional requirements of students for innovation and entrepreneurship platforms will also be different. Therefore, it is necessary for the college to deeply understand the needs of students for innovation and entrepreneurship, and build different types and different levels of innovation and entrepreneurship practice platforms that meet the needs of the major, so as to form a unified and efficient practice and education platform system.

\subsection{Quality Standards for Professional Talent Training Need to be Established}

The Outcome-Oriented Education (OBE) concept with "student-centered, output-oriented, and persistent improvement" as its core has become the standard for domestic engineering education professional certification. The standard emphasizes student output to drive the operation of the education system. Educators first envision students' future career achievements, conceive the abilities and levels that students should achieve upon graduation, and then design appropriate curriculum structures and teaching projects to ensure that students meet these expectations Target. In the new era, it is necessary to explore the quality standards for the training of professional talents in automation control based on the professional certification standards of engineering education, to provide a basis for the training process of professional talents, and to provide guarantees for the quality of talent training.

\section{Innovation and Entrepreneurship Platform System Design}

\subsection{Principles of System Design}

As the upsurge of mass entrepreneurship and innovation continues, vocational students have become one of the most active activists. The entrepreneurial management system for higher 
vocational students based on the B/S structure can help managers supervise and manage the expected benefits. It is a promising entrepreneurial project [4]. The system is mainly divided into 11 modules, including startup project establishment, application deadline, application process, teacher, school level and field expert team project and audit project progress report, summary and data summary, important data backup, etc. The overall design standards of the system follow the principles of availability, ease of use, security, maintainability, scalability, and compatibility.

\subsection{System Architecture Design}

The entrepreneurial management system for higher vocational students mainly uses the Oracle database application of the data storage system and the development of the $\mathrm{C}$ language and Studio.NET integrated platform system, and combines the network framework technology to modify the system, thereby completing the design and implementation of the $\mathrm{B} / \mathrm{S}$ structure (figure 1). Vocational student entrepreneurship management system is mainly divided into time setting module, parameter setting module, engineering application expert group module, project review module, project publicity module, project progress module, recording module, mid-term report module, project summary module, data query and statistics 11 major functional modules such as module and data backup file module. Provide infrastructure module support for system operation by using databases, operating systems, intermediate devices, short message services, etc., so as to build a communication operation platform software system. Based on the integrated development structure of the .NET framework and the third layer of the B/S structure, fully considering the requirements and practical application of the system, based on the business application system planning of the 11 major functional modules, the corresponding modules are subdivided into Different modules; the fourth layer is various application systems, data resources, network resources, integrated information management platform and other office environments, and based on its own characteristics and functions, it forms a personalized application interface.

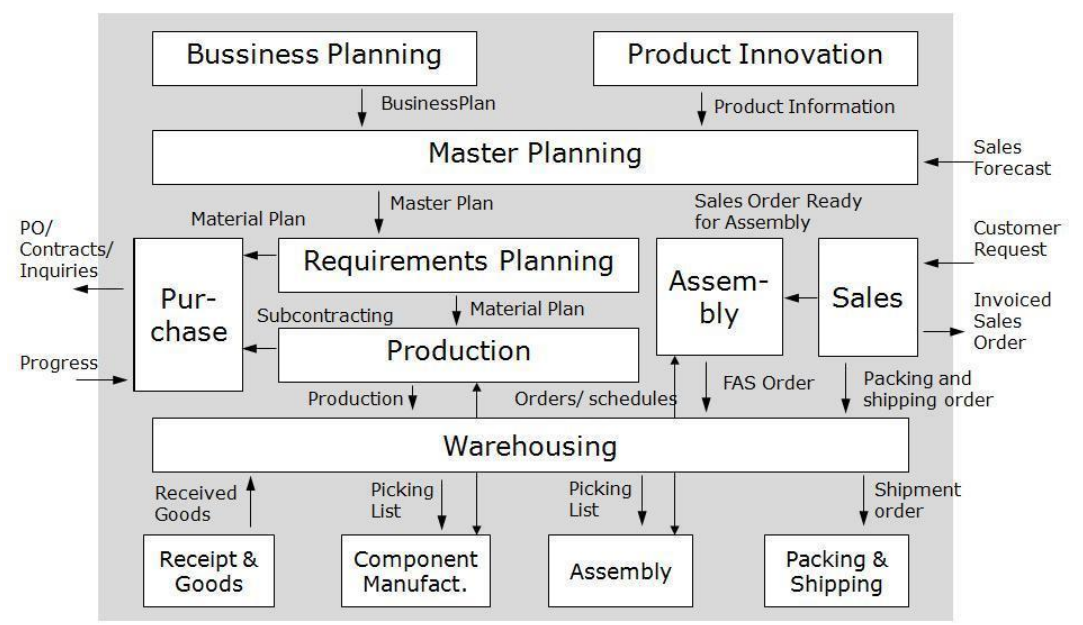

Fig 1. School entrepreneurship system architecture

\subsection{Database Design}

Database design is the process of designing and constructing the entire database in a specific information system according to the different needs of users (Figure 2). The whole design process is mainly divided into 6 steps: user demand analysis, database concept structure design, logical hierarchy design, physical structure design, implementation and maintenance of the database. The concept of the entity-relationship data model is to describe the concept of entities in the real world through the use of entity-connection diagrams, rather than realizing these entities in the real world. In the $\mathrm{B} / \mathrm{S}$ structure of the higher vocational student entrepreneurship management system, the students, teachers, and university experts involved are entity relationship data models, including basic project information and project specifications. 
Volume 3 (2021)

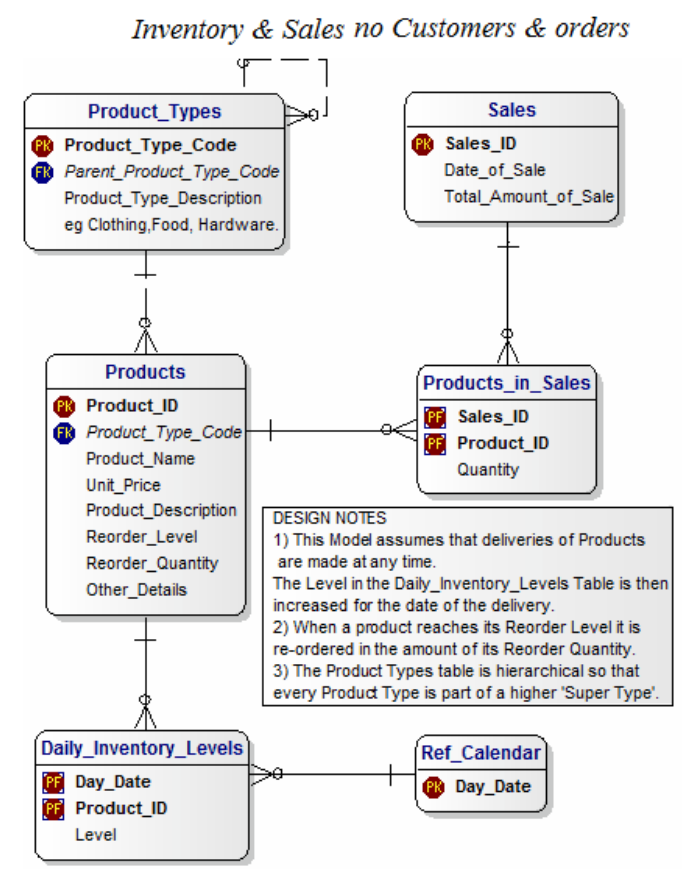

Complex Inventory \& Sales with Customers \& Orders

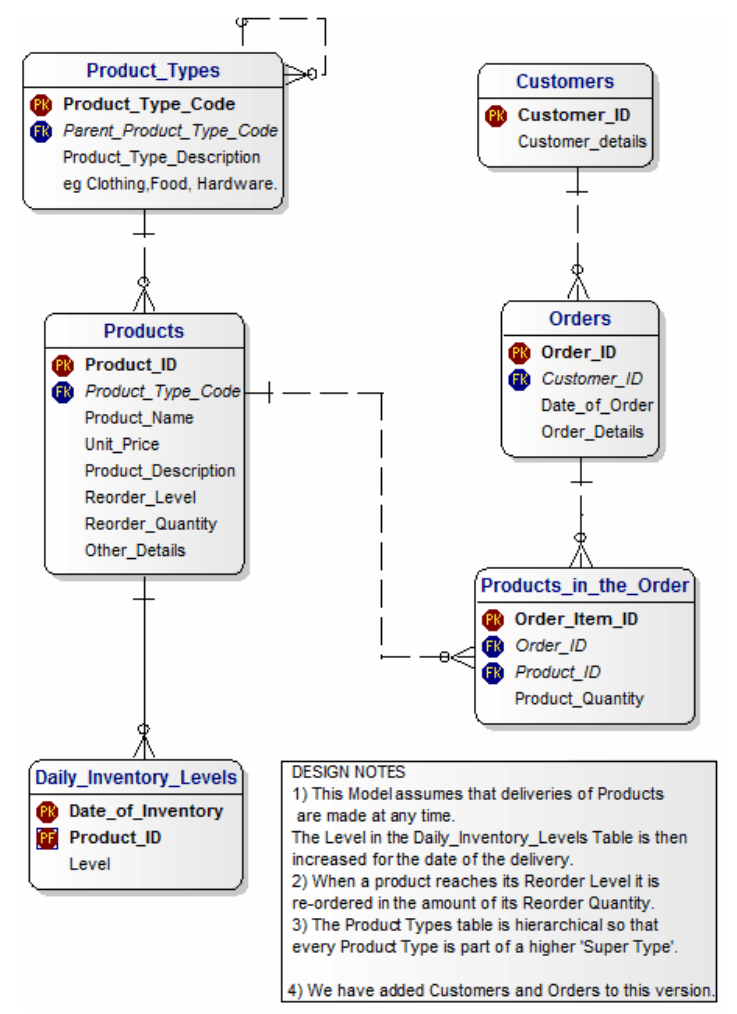

E-Inventory Management System

Fig 2. Entrepreneurship system database

\subsection{Function Module}

(1) Provide a platform

Through the development of higher vocational students' innovation and entrepreneurship information service platform software, the display of the innovation and entrepreneurship process of higher vocational students is realized.

(2) Realize 2 management

Namely innovation and entrepreneurship project management and innovation and entrepreneurship competition management. Develop innovative and entrepreneurial project management software to help schools, instructors, and students collaborate in the division of labor, organize and maintain innovative and entrepreneurial teams, and achieve overall project management, including simultaneous implementation of online project process management, mid-term KPI assessment, and online project completion, Archiving, statistics and query functions [5]. Develop innovation and entrepreneurship competition management software to build an integrated "competition management platform", and support various online functions of the competition including "Internet + Higher Vocational Student Innovation and Entrepreneurship Plan", from the release of competition information, registration to competition at the end, all queries can be made on the Internet to realize data sharing. Through the competition management software, students are encouraged to actively participate in the competition and improve the efficiency of the competition. Select outstanding innovation and entrepreneurship results and teams through competitions, reviews, incubation and other evaluation methods to realize the internal and external docking of entrepreneurs and promote the success rate of actual entrepreneurship.

(3) Achieve 3 kinds of cloud applications

That is, innovative cloud applications, employment cloud applications, and entrepreneurial cloud applications. Innovative cloud applications, create IoT platforms for various experimental objects, unify ubiquitous objects into computer network objects, and support their interconnection and interoperability. Through innovative practical software, the entrepreneurial education and 
professional education are fully integrated, relying on various professional laboratories to build a unified data stream, video stream and control stream channel, forming a multi-disciplinary coverage skill practice system, and realizing the students during the school period Have the opportunity to participate in innovative training practices. The employment cloud application aims at the ambiguous employment needs and detailed job requirements of enterprises, the ambiguous job search needs of students and the detailed education process, through the collaborative employment cloud using semantic analysis methods to achieve precise push to achieve intelligent matching of employment information. Entrepreneurship cloud application, through a series of project training, students master the team formation method, understand the policy orientation, complete virtual entrepreneurship, through the knowledge base and rule library provided by the cloud service platform, and finally through real registration, complete the process from virtual entrepreneurship to actual entrepreneurship transition. The functional modules of the new engineering practice platform are shown in Figure 3.

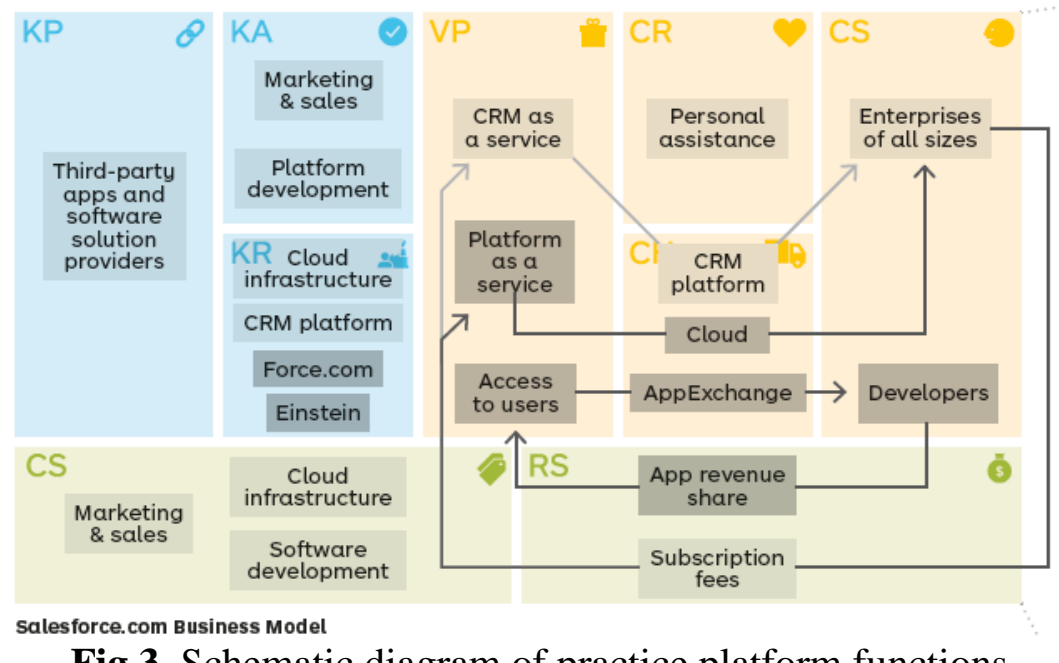

Fig 3. Schematic diagram of practice platform functions

\section{4. "Integrated" Innovation Platform Center Application Practice}

In recent years, the automation control professional innovation platform center has used the "practical training + innovation and entrepreneurship" integrated innovation platform center, based on the integrated innovation and entrepreneurship project, carried out a series of educational activities such as practical training, innovation and entrepreneurship, and training competitions in different disciplines. The formation of new, lectures, training, elective innovation and general education courses among first-year students to cultivate innovation awareness; second-year students enter relevant innovation and entrepreneurship platforms to participate in innovation projects, scientific innovation activities, intramural competitions, national innovation programs, etc. Initial innovation and entrepreneurship training; third-year students participate in special training, various competition training, innovation competitions at all levels, etc., to cultivate innovation and entrepreneurship practice capabilities. In order to encourage students to actively participate in various forms of practical training and innovation and entrepreneurship training activities, the school has established 4 honorary credits for innovation and entrepreneurship education [6]. The honorary credits of innovation and entrepreneurship education require "tuition-free, compulsory for all employees, and graduates after completing the course." These measures have effectively promoted the "whole process, wide coverage, universal benefit, and sustainable" development of practical training and innovation and entrepreneurship education. Table 1 shows the number of beneficiaries of the integrated innovation platform center of "Practice Training + Innovation and Entrepreneurship" from 2012 to 2020. Higher vocational students inside and outside the school benefited a total of 87,588 persontimes, of which 76,249 person-times were benefited on campus, and 1,339 person-times were benefited from off-campus. 
Table 1. Summary of the Number of Beneficiaries of the "Practice Training + Innovation and Entrepreneurship" Integrated Innovation Platform Center from 2012 to 2020

\begin{tabular}{|c|c|c|c|c|c|c|c|c|c|c|}
\hline & $\mathbf{2 0 1 2}$ & $\mathbf{2 0 1 3}$ & $\mathbf{2 0 1 4}$ & $\mathbf{2 0 1 5}$ & $\mathbf{2 0 1 6}$ & $\mathbf{2 0 1 7}$ & $\mathbf{2 0 1 8}$ & $\mathbf{2 0 1 9}$ & $\mathbf{2 0 2 0}$ & Total \\
\hline On campus & 5765 & 4818 & 5959 & 5221 & 7752 & 8954 & 11515 & 12607 & 13658 & 76249 \\
\hline Off-campus & 1290 & 261 & 1187 & 1526 & 865 & 540 & 1549 & 1135 & 2986 & 11339 \\
\hline total & 7055 & 5079 & 7146 & 6747 & 8617 & 9494 & 13064 & 13742 & 16644 & 87588 \\
\hline
\end{tabular}

\section{Conclusion}

In order to promote the realization of the goal of the integrated training of practice, innovation, and entrepreneurship for higher vocational students, the four platforms "engineering cognition training, engineering skills training, engineering comprehensive training, and innovation and entrepreneurship training are the four platforms, integrating knowledge, ability, and quality education., The integrated innovation platform center system of "practical training + innovation and entrepreneurship" in which ability training runs through the whole process. Using this system to carry out integrated training of practice, innovation, and entrepreneurship for students majoring in automation control in higher vocational schools, which embodies the student-centered education concept, and is conducive to higher vocational students to improve their comprehensive abilities, achieve ability stacking, carry out independent learning, and develop well. Values, cultivate team spirit, cultivate innovation ability and entrepreneurial ability. It has important practical significance and promotion and application value for improving the effectiveness of training innovative and entrepreneurial talents, implementing innovation-driven development strategies, building an innovative country, and cultivating a large number of innovative and entrepreneurial talent teams who are creative, good at innovation and entrepreneurial.

\section{Acknowledgments}

Fund Project: Social Science Project of the 13th Five-Year Plan of Jilin Provincial Department of Education "Research on Practice Platform and Operation Mode of Innovation and Entrepreneurship for Higher Vocational College Students" (JJKH20200229JY).

\section{References}

[1] Tedja, A. A. Wijaya, V. A. \& Lidyawati, J. Automatic Exchange of Information on Indonesia Jurisdiction in order to Control Business Opportunities. Notaire, vol. 2, pp.143-156, February 2019.

[2] Srivastava, A. K. Khan, R. \& Jain, S. A tool for generation of automatic control flow graph in unit testing of python programs. Int J Eng Adv Technol (IJEAT), vol. 8, pp. 1178-1184, May 2019.

[3] Sabatucci, L. \& Cossentino, M. Supporting dynamic workflows with automatic extraction of goals from BPMN. ACM Transactions on Autonomous and Adaptive Systems (TAAS), vol. 14, pp.1-38, February 2019.

[4] Waszkowski, R. Low-code platform for automating business processes in manufacturing. IFAC-Papers OnLine, 52, pp.376-381, October 2019.

[5] Wang, S. Peng, X. Lü, Q. Long, F. Jiang, Y. \& Meng, Y. Design and implementation of the overall architecture of the Puguang intelligent gas-field project. Natural Gas Industry B, vol. 6, pp. 262-271, March 2019.

[6] Muniandi, G. Blockchain-enabled virtual coupling of automatic train operation fitted mainline trains for railway traffic conflict control. IET Intelligent Transport Systems, vol. 14, pp. 611-619, June 2020. 